\title{
Enhancing the Hygienic Quality of Some Ghanaian Food Products by Gamma Irradiation
}

\author{
Abraham Adu-Gyamfi ${ }^{*}$, Victoria Appiah \\ Department of Food Science and Radiation Processing, Biotechnology \& Nuclear Agriculture Research Institute, Ghana Atomic \\ Energy Commission, Accra, Ghana. \\ Email: *adugyamfi21@yahoo.com
}

Received September $10^{\text {th }}, 2011$; revised November 30 ${ }^{\text {th }}, 2011$; accepted December $7^{\text {th }}, 2011$

\begin{abstract}
The microbiological quality (microbial load and profile) of 6 Ghanaian food products was determined before and after irradiation (0 kGy, 5 kGy, 7.5 kGy, $10 \mathrm{kGy)}$ using standard microbiological methods. The microbial load was estimated by the total viable count (TVC) and moulds and yeasts count (MYC). The range of TVC and MYC of the un-irradiated products were $10^{3} \mathrm{cfu} / \mathrm{g}-10^{6} \mathrm{cfu} / \mathrm{g}$ and $0 \mathrm{cfu} / \mathrm{g}-10^{6} \mathrm{cfu} / \mathrm{g}$ respectively. Un-irradiated Banku Mix Powder, Fermented Maize Powder and Cassava Dough Powder had relatively low microbial load (TVC $\leq 6.1 \times 10^{3} \mathrm{cfu} / \mathrm{g}$; MYC $\leq 4.9 \times 10^{2}$ cfu/g). Un-irradiated Fermented Maize Dough, Kokonte Powder and Cassava Dough had relatively high TVC of $>10^{6}$ cfu/g. Eleven and 3 microbial isolates were detected in the un-irradiated and irradiated products respectively and the most common were Aspergillus niger and Bacillus spp. Irradiation dose of $10 \mathrm{kGy}$ eliminated all microorganisms from the products. Doses of 5 and $7.5 \mathrm{kGy}$ reduced the microbial loads of the products by approximately 1 to $6 \log$ cycles to meet national and international standards. The use of low dose gamma radiation by the local food industry could improve the hygienic quality, extend shelf-life and enhance the competitiveness of the Ghanaian food products in domestic and export markets.
\end{abstract}

Keywords: Hygienic Quality; Gamma Irradiation; Ghanaian Food Products

\section{Introduction}

The production of indigenous foods forms a major part of agro-industries that accounts for over $50 \%$ of value-added manufacturing, exports and employment in most African countries including Ghana [1]. Fermented maize and cassava products such as maize dough, cassava dough, and kokonte (dried cassava powder) contribute significantly to the food security situation in the country due to their availability, affordability, nutritional quality and inherent preservative properties.

Traditionally, these foods are well-preserved through biochemical processes involving alcoholic and acidic fermentations that lower $\mathrm{pH}$ and prevent the growth of diseasecausing microorganisms [2,3]. Studies have shown lactic acid bacteria, which forms the most dominant microflora in most traditionally fermented foods, inhibit the growth of foodborne pathogens such as Salmonella spp., Shigella spp., Escherichia coli, and Staphylococcus aureus in some foods $[4,5]$.

However, despite the inherent preservative properties of fermented foods, the artisanal nature of their production results in products of varying and poor quality. Cassava and

${ }^{*}$ Corresponding author. maize products are frequently exposed to contamination due to deficiencies in processing methods, such as insufficient and uncontrolled drying as well as defective packaging. Open sun drying of such foods results in con- tamination by insects, bacteria and moulds. Mycological studies have confirmed the presence of several toxigenic fungi on maize [6] and prevailing high temperatures and relative humidities in the country promote the production of mycotoxin in foods including kokonte [7] and maize [8]. Aflatoxin levels of $0.7 \mu \mathrm{g} \cdot \mathrm{kg}^{-1}$ to $313 \mu \mathrm{g} \cdot \mathrm{kg}^{-1}$ of maize dough have been reported [8]. These findings have seious health implications since some mycotoxins are carcinogenic, mutagenic and teratogenic $[9,10]$.

In order to accelerate the commercialization of indigenous foods, it is imperative to improve their hygienic quality to ensure their competitiveness in both local and international markets. Irradiation is one of the few processes that can help attain this goal. The use of irradiation as a decontaminating process without loss of sensory and organoleptic qualities, is well documented for various foods [11-14]. Perusal of literature indicates very scanty information on the application of irradiation to improve the hygienic quality of Ghanaian food products for domestic and export markets. The objective of this study was there- 
fore to investigate the use of gamma irradiation in the decontamination of some local (Ghanaian) food products so as to improve their hygienic quality.

\section{Materials and Methods}

\subsection{Samples and Irradiation}

Six samples of local (Ghanaian) food products used for the study were mainly fermented maize and cassava products submitted by some local food processing companies for contract irradiation at the Radiation Technology Centre (RTC) of Ghana Atomic Energy Commission (GAEC). The samples were:

1) Banku Mix Powder (mixture of fermented maize dough and cassava dough);

2) Fermented Maize Powder;

3) Fermented Maize Dough;

4) Kokonte Powder (cassava powder);

5) Cassava Dough;

6) Casava Dough Powder.

\subsection{Irradiation}

Five grammes of each product was packaged in a polyethylene pouch and sealed using a heat sealer (Heat Sealer, Desk Type: $300 \mathrm{~m} / \mathrm{m}$, Taiwan). The pouches were treated with irradiation doses of $0,5.0,7.5$, and $10.0 \mathrm{kGy}$ at the RTC of GAEC using a $\mathrm{Co}^{60}$ source (SLL-515, Hungary) at a dose rate of $2.55 \mathrm{kGy} / \mathrm{hr}$ in air. The absorbed dose was confirmed by Fricke's dosimetry.

\subsection{Determination of Microbial Load}

After irradiation, both controls and irradiated food products were analysed for their microbial load. One gramme of each sample was added to $9 \mathrm{ml}$ peptone water (1\% peptone $+0.5 \% \mathrm{NaCl}$ ) and placed on a mechanical shaker (Junior Orbital Shaker, Lab-line Instruments, USA) for 15 minutes. The mixture was then allowed to settle for about 5 minutes to allow coarse material to settle down. Microbial load determination was carried out on the supernatant using standard decimal and plate count methods [15].

1) Total viable counts on Plate count agar (Oxoid, UK) at $36^{\circ} \mathrm{C}$ for 48 hours.

2) Moulds and yeasts on Oxytetracycline ( $0.01 \%)$ glucose yeast agar (Merck, Germany) at $28^{\circ} \mathrm{C}$ for 72 hours.

For each product the average of two estimations of duplicate plating was carried out.

Representative colonies from the plate counts were purified by sub-culturing and identified using morphological characteristics and biochemical tests (Gram stain, catalase test, oxidase test, motility test) with reference to Biochemical Tests for Identification of Medical Bacteria [16, 17]. Yeasts were counted but types were not identified.

\section{Results}

The ranges of total viable count (TVC) and moulds and yeasts count (MYC) for the un-irradiated food products were $10^{3} \mathrm{cfu} / \mathrm{g}-10^{6} \mathrm{cfu} / \mathrm{g}$ and $0 \mathrm{cfu} / \mathrm{g}-10^{6} \mathrm{cfu} / \mathrm{g}$ respecttively (Tables 1 and 2). Un-irradiated samples of Banku Mix Powder, Fermented Maize Powder and Cassava Dough Powder had very low TVC and MYC of $<10^{4}$ cfu/g. Un-irradiated samples of Fermented Maize Dough, Kokonte Powder and Cassava Dough had relatively high TVC of $>10^{6} \mathrm{cfu} / \mathrm{g}$. A high MYC $\left(>10^{5} \mathrm{cfu} / \mathrm{g}\right)$ was recorded for un-irradiated samples of Fermented Maize Dough and Cassava Dough.

A total of 11 microbial isolates (8 fungal and 3 bacterial isolates) were detected in the un-irradiated products (Table 3). Six isolates were detected in un-irradiated Ban$k u$ Mix Powder and 1 each were detected in un-irradiated samples of Cassava Dough and Cassava Dough Powder. The most common isolates in the products were Aspergillus niger and Bacillus spp.

Table 1. Total viable count (cfu/g) of some Ghanaian food products after irradiation.

\begin{tabular}{|c|c|c|c|c|c|c|c|c|}
\hline \multirow{2}{*}{ Product } & \multicolumn{2}{|r|}{${ }^{\mathrm{a}} 0 \mathrm{kGy}$} & \multicolumn{2}{|r|}{5 kGy } & \multicolumn{2}{|r|}{7.5 kGy } & \multicolumn{2}{|c|}{10 kGy } \\
\hline & Mean & Range & Mean & Range & Mean & Range & Mean & Range \\
\hline Banku Mix Powder & ${ }^{\mathrm{b}} 4.0 \times 10^{3}$ & ${ }^{\mathrm{c}} 5.0 \times 10^{2}-7.5 \times 10^{3}$ & $7.0 \times 10$ & $2.0 \times 10-1.2 \times 10^{2}$ & $<10$ & $<10$ & $<10$ & $<10$ \\
\hline Fermented Maize Powder & $6.1 \times 10^{3}$ & $4.2 \times 10^{3}-8.0 \times 10^{3}$ & $5.0 \times 10$ & $3.0 \times 10-7.0 \times 10$ & $<10$ & $<10$ & $<10$ & $<10$ \\
\hline Fermented Maize Dough & $1.9 \times 10^{6}$ & $8.0 \times 10^{5}-3.0 \times 10^{6}$ & $2.3 \times 10^{5}$ & $4.0 \times 10^{4}-4.2 \times 10^{5}$ & $1.1 \times 10^{2}$ & $9.0 \times 10-1.3 \times 10^{2}$ & $<10$ & $<10$ \\
\hline Kokonte Powder & $8.3 \times 10^{6}$ & $4.6 \times 10^{2}-1.2 \times 10^{7}$ & $2.3 \times 10^{3}$ & $6.0 \times 10^{2}-4.0 \times 10^{3}$ & $1.1 \times 10$ & $8.0 \times 10-1.4 \times 10^{2}$ & $<10$ & $<10$ \\
\hline Cassava Dough & $7.0 \times 10^{6}$ & $3.0 \times 10^{5}-7.0 \times 10^{6}$ & $1.0 \times 10^{4}$ & $7.0 \times 10^{3}-1.3 \times 10^{4}$ & $2.0 \times 10$ & $1.0 \times 10-3.0 \times 10$ & $<10$ & $<10$ \\
\hline Cassava Dough Powder & $1.0 \times 10^{3}$ & $4.2 \times 10^{2}-1.6 \times 10^{3}$ & $3.5 \times 10^{2}$ & $2.0 \times 10^{2}-5.0 \times 10^{2}$ & $<10$ & $<10$ & $<10$ & $<10$ \\
\hline
\end{tabular}

${ }^{\mathrm{a}}$ Un-irradiated control, ${ }^{\mathrm{b}}$ means of triplicate samples, ${ }^{\mathrm{c}}$ range of 3 samples; limit of detection $=10$. 
Table 2. Mould and yeasts count (cfu/g) of some Ghanaian food products after irradiation.

\begin{tabular}{|c|c|c|c|c|c|c|c|c|}
\hline \multirow{2}{*}{ Product } & \multicolumn{2}{|r|}{${ }^{\mathrm{a}} 0 \mathrm{kGy}$} & \multicolumn{2}{|r|}{5 kGy } & \multicolumn{2}{|r|}{7.5 kGy } & \multicolumn{2}{|c|}{$10 \mathrm{kGy}$} \\
\hline & Mean & Range & Mean & Range & Mean & Range & Mean & Range \\
\hline Banku Mix Powder & $<10$ & $<10$ & $<10$ & $<10$ & $<10$ & $<10$ & $<10$ & $<10$ \\
\hline Fermented Maize Powder & $\mathrm{b}_{5} 5.0 \times 10$ & ${ }^{\mathrm{c}} 4.0 \times 10-6.0 \times 10$ & $<10$ & $<10$ & $<10$ & $<10$ & $<10$ & $<10$ \\
\hline Fermented Maize Dough & $6.0 \times 10^{6}$ & $2.5 \times 10^{6}-9.5 \times 10^{6}$ & $5.0 \times 10^{4}$ & $2.5 \times 10^{6}-9.5 \times 10^{6}$ & $5.0 \times 10$ & $3.0 \times 10-7.0 \times 10$ & $<10$ & $<10$ \\
\hline Kokonte Powder & $1.0 \times 10^{3}$ & $4.0 \times 10^{2}-1.6 \times 10^{3}$ & $3.0 \times 10$ & $2.0 \times 10-4.0 \times 10$ & $<10$ & $<10$ & $<10$ & $<10$ \\
\hline Cassava Dough & $5.9 \times 10^{5}$ & $1.8 \times 10^{5}-1.0 \times 10^{6}$ & $2.3 \times 10^{2}$ & $1.0 \times 10^{2}-3.6 \times 10^{2}$ & $3.0 \times 10$ & $2.0 \times 10-4.0 \times 10$ & $<10$ & $<10$ \\
\hline Cassava Dough Powder & $4.9 \times 10^{2}$ & $8.0 \times 10-9.0 \times 10^{2}$ & $8.0 \times 10$ & $6.0 \times 10-1.0 \times 10^{2}$ & $<10$ & $<10$ & $<10$ & $<10$ \\
\hline
\end{tabular}

${ }^{\mathrm{a}}$ Un-irradiated control, ${ }^{\mathrm{b}}$ means of triplicate samples, ${ }^{\mathrm{c}}$ range of 3 samples; limit of detection $=10$.

Table 3. Presence of microbial isolates in irradiated and un-irradiated Ghanaian food products.

\begin{tabular}{|c|c|c|}
\hline Isolate & Un-irradiated Product & ${ }^{\mathrm{a}}$ Irradiated Product \\
\hline Aspergillus niger & ${ }^{\mathrm{b}} 1,2,3,4$ & 3,4 \\
\hline Aspergillus versicolor & 1,2 & - \\
\hline Aspergillus candidus & 1,2 & - \\
\hline Aspergillus wentii & 4 & - \\
\hline Alternaria spp. & $1,2,4$ & 4 \\
\hline Penicillium spp. & 1 & - \\
\hline Rhizopus spp. & 4 & - \\
\hline Lactobacilllus spp. & 3 & - \\
\hline Bacillus spp. & $1,2,3,4,5$ & 3 \\
\hline Staphylococcus spp. & 4 & - \\
\hline Geotrichum spp. & 6 & - \\
\hline
\end{tabular}

irradiated at 7.5 kGy, ${ }^{\text {b }}$ not detected, ${ }^{\mathrm{c}} 1$ = Banku Mix Powder, 3 = Fermented Maize Dough, 5 = Cassava Dough, 2 = Fermented Maize Powder4 = Kokonte Powder, 6 = Cassava Dough Powder.

Irradiating the food products reduced the microbial load significantly. A dose of $10 \mathrm{kGy}$ eliminated all microflora from the products. Additionally, $7.5 \mathrm{kGy}$ eliminated all microflora from the products with the exception of Fermented Maize Dough, Kokonte Powder and Cassava Dough in which microbial loads were reduced to $\leq 1.1 \times 10^{2}$ cfu/g. The originally low TVC and MYC of Banku Mix Powder, Fermented Maize Powder and Cassava Dough Powder were further reduced by irradiation to very low values of $\leq 3.5 \times 10^{2} \mathrm{cfu} / \mathrm{g}$.

However, in the case of the other irradiated food products, a dose of $5 \mathrm{kGy}$ reduced TVC to $<10^{4}$ and MYC to $<10^{3}$ with the exception of Fermented Maize Dough.

\section{Discussion}

The hygienic quality of the un-irradiated food products as estimated by the TVC and MYC, showed wide variations. Although some variation are to be expected due to the nature of the indigenous microflora, the observed variations were wide and could be attributed to lack of standard processing procedures and contamination. The microbial load of un-irradiated samples of Banku Mix Powder, Fermented Maize Powder and Cassava Dough Powder were very low indicating high product quality. Un-irradiated samples of Fermented Maize Dough, Kokonte Powder and Cassava Dough had high microbial loads and this was attributed to deficiencies in production protocols. 
Generally, the doughs (Fermented Maize Dough and Cassava Dough) had high microbial loads, possibly due to their semi-dried nature and consequently high water activity. On the other hand, the un-irradiated powders (Fermented Maize Powder, Cassava Dough Powder) with the exception of Kokonte Powder, had low microbial loads. The high TVC of Kokonte Powder could probably be due to contamination arising out of the open-air exposure when cassava chips are dried. Considering the microorganisms isolated from the un-irradiated food products, it was noted that Bacillus spp., Geotrichum spp. and Lactobacillus spp were part of the normal fermentation microflora of maize and cassava. However, the presence of various species of Aspergillus, Pennicillium spp., Rhizopus spp. and Staphylococcus spp. could be attributed to contamination.

Irradiation was effective in reducing the microbial load of the food products and eliminating most of their microbial contaminants. A dose of $10 \mathrm{kGy}$ completely eliminated all microorganisms from the products. Doses of 5 and $7.5 \mathrm{kGy}$ reduced the TVC and MYC of all the products by 1 to 6 log cycles. Although a dose of $7.5 \mathrm{kGy}$ was more effective in reducing the microbial load and eliminating microbial isolates, the results seem to suggest that improving the quality and degree of drying of the dough (Cassava and Maize) and Kokonte Powder could possibly reduce the effective decontamination dose from 7.5 to 5 kGy. This observation underscores the need for Good Manufacturing Practices (GMP) in production protocols to ensure products have low and acceptable hygienic quality. To this end, the use of alternate methods of drying such as solar and oven drying is recommended as a measure to improve to quality of drying of fermented foods. Irradiation with $5 \mathrm{kGy}$ would be in line with the national criteria for decontamination of dry foods which specifies that dose as the effective and applicable dose [18].

Aside reducing the microbial load, it is essential that pathogenic and toxigenic isolates are eliminated from foods products. The presence of various species of Aspergillus, Penicillium spp., Rhizopus spp. and Staphylococcus spp. in some of the food products raises food safety concerns. Apart from fact that $10 \mathrm{kGy}$ eliminated all isolates, irradiation with $7.5 \mathrm{kGy}$ also eliminated 7 out of the 11 isolates found in the food products. This is to be expected since irradiation is one of the few processes that eliminates disease-causing microorganisms from foods and guarantees high hygienic quality. Using irradiation as a decontamination process could reduce the presence of pathogenic and toxigenic microorganisms and help improve the hygienic quality of food products to meet national and international standards [TVC $<10^{6} \mathrm{cfu} / \mathrm{g}$ and MYC $<10^{4}$ cfu/g $[19,20]$. This study has demonstrated the possibility of using low doses of gamma radiation to improve the hygienic quality and extend the shelf-life of various Ghanaian food products, thus making them competitive on both domestic and export markets.

\section{Conclusion}

Ghanaian food products vary in their hygienic quality due to differences in their indigenous microflora, processing and storage protocols. Although irradiation doses of 10 and 7.5 kGy significantly reduced microbial load to internationally accepted levels and eliminated most microbial isolates, $5 \mathrm{kGy}$ could be used if good manufacturing practices are employed in production protocols to improve product quality. The application of low-dose gamma radiation by the local food industry would improve the hygienic quality and extend shelf-life of the Ghanaian food products to enhance their competitiveness in domestic and export markets.

\section{Acknowledgements}

The authors gratefully acknowledge the technical assistance of Messrs E. Akolmolga, T. Mahami, C. Owulah and D. Datohe of the Department of Food Science and Radiation Processing, BNARI/GAEC.

\section{REFERENCES}

[1] United Nations Industrial Development Organization, "Food Processing Technologies for Africa," In: H. A. Dirar, Ed., UNIDO, Vienna, 1997.

[2] A. Reilly and A. Westby, "Food Fermentations-Traditional Low-Cost Food Preservation Systems,” In: H. A. Dirar, Ed, Food Processing Technologies for Africa, UNIDO, Vienna, 1997.

[3] R. D. Pace, W. A. Plahar and J. Y. Lu, "Status of Traditional Food Preservation Methods for Selected Ghanaian Foods,” Foods Review International, Vol. 5, No. 1, 1989, pp. 1-12. doi:10.1080/87559128909540842

[4] M. J. R. Nout, F. M. Rombouts and A. Havelaar, "Effect of Accelerated Natural Lactic Fermentation of Infant Food Ingredients on Some Pathogenic Bacteria,” International Journal of Food Microbiology, Vol. 8, No. 4, 1989, pp. 351-361. doi:10.1016/0308-8146(95)00155-7

[5] S. K. Mbugua and I. Njenga, "Anti-Microbial Properties of Fermented Uji as a Weaning Food,” In: A. Westby and P. J. A. Reilly, Eds., Proceedings of a Regional Workshop on Traditional African Foods-Quality and Nutrition. 25-29 November 1991, Stockholm, 1992, pp. 63-68.

[6] L. Jesperson, M. Halm, K. Kpodo and M. Jakobsen, “The Significance of Yeasts and Moulds Occurring in Maize Dough Fermentation for 'Kenkey' Production,” International Journal of Food Microbiology, Vol. 24, No. 1-2, 1994, pp. 293-298.

[7] P. Wareing, "Report on a Visit to Ghana to Determine the Incidence and Extent of Mould and Mycotoxin Contamination in Cassava Products,” NRI Report R2011, Falls Church, 1993.

[8] K. A. Kpodo, A. K. Sorenson and M. Jacobsen, "The Occurrence of Mycotoxins in Fermented Maize Products," Food Chemistry, Vol. 56, No. 20, 1996, pp. 147153. doi:10.1016/0308-8146(95)00155-7 
[9] D. L. Eaton and J. D. Groopman, “The Toxicology of Aflatoxins. Human Health, Veterinary and Agricultural Significance,” Academic Press, San Diego, 1994.

[10] F. P. Guengerich, W. W. Johnson, Y. F. Veng and T. Shimade, "Involvement of Cytochrome P450, Glutathione S-Transferase and Epoxide Hydrolase in the Metabolism of Aflatoxin $\mathrm{B}_{1}$ and Relevance to Risk of Human Liver Cancer,” Environmental. Health Perspectives, Vol. 104, 1996, pp. 557-562.

[11] J. Farkas, "Irradiation of Dry Food Ingredients," CRC Press Inc., Boca Raton, 1988, pp. 39-44,67-69.

[12] Council for Agricultural Science and Technology (CAST), "Radiation Pasteurisation of Food," Issue Paper No. 7, CAST, Ames, 1996.

[13] International Atomic Energy Agency (IAEA), TECDOC639, Vienna, 1992.

[14] American Society for Testing and Materials (ASTM), "Standard Guide for Irradiation of Spices, Herbs and Ve- getable Seasoning to Control Pathogens and other Microorganisms,” ASTM Standard F 1885-98, Denver, 1998.

[15] American Public Health Association (APHA), "Compendium of Methods for the Microbiological Examination of Foods,” In: M. K. Speck, Ed., American Public Health Association, Washington DC, 1996.

[16] J. F. MacFaddin, "Biochemical Tests for Identification of Medical Bacteria,” Williams and Wilkins, Baltimore, 1980.

[17] J. C. Gilman, “A Manual of Soil Fungi,” Iowa State University Press, Annes, 1957.

[18] Ghana Standards, Reference No. GS 210, Ghana Standards Board, Accra, 1998.

[19] Y. S. Lewis, "Spices and Herbs for the Food Industry," Food Trade Press, Orpington, 1984.

[20] Ghana Standards, Reference Nos. GS 235: 1997; GS236: 1997. Ghana Standards Board, Accra, 1997. 